This paper has to be cited as: Tomás, R., Li, Z., Lopez-Sanchez, J.M., Liu, P. \& Singleton, A. 2016. Using wavelet tools to analyse seasonal variations from InSAR time-series data: a case study of the Huangtupo landslide. Landslides, 13, 437-450, The final publication is available at Springer via: https://link.springer.com/article/10.1007\%2Fs10346-015-0589-y

\title{
Using wavelet tools to analyse seasonal variations from InSAR time- series data: a case study of the Huangtupo landslide
}

\author{
R. Tomás ${ }^{1}$, Z. Li ${ }^{2}$, J.M. Lopez-Sanchez ${ }^{3}$, P. Liư ${ }^{4}$, A. Singleton ${ }^{2}$
}

(1) Departamento de Ingeniería Civil, Escuela Politécnica Superior, Universidad de Alicante P.O. Box 99, E-03080 Alicante, Spain

(2) COMET, School of Civil Engineering and Geosciences, Newcastle University, Newcastle upon Tyne, NE1 7RU, UK.

(3) Instituto Universitario de Investigación Informática, Universidad de Alicante P.O. Box 99, E-03080 Alicante, Spain

(4) Key Laboratory for Geo-Environment Monitoring of Coastal Zone of the National Administration of Surveying, Mapping and Geo-Information, College of Information Engineering, Shenzhen University, Shenzhen 518060, China.

\begin{abstract}
Synthetic Aperture Radar Interferometry (InSAR) has proven to be a powerful tool for monitoring landslide movements with a wide spatial and temporal coverage. Interpreting landslide displacement time-series derived from InSAR techniques is a major challenge for understanding relationships between triggering factors and slope displacements. In this study, we propose the use of various wavelet tools, namely Continuous Wavelet Transform (CWT), Cross Wavelet Transform (XWT) and Wavelet Coherence (WTC) for interpreting InSAR time-series information for a landslide. CWT enables time-series records to be analysed in time-frequency space, with the aim of identifying localized intermittent periodicities. Similarly, XWT and WTC help identify the common power and relative phase between two time-series records in time-frequency space, respectively. Statistically significant coherence and confidence levels against red noise (also known as brown noise or random walk noise) can be calculated. Taking the Huangtupo landslide (China) as an example, we demonstrate the capabilities of these tools for interpreting InSAR time-series information. The results show the Huangtupo slope is affected by an annual displacement periodicity controlled by rainfall and
\end{abstract}


This paper has to be cited as: Tomás, R., Li, Z., Lopez-Sanchez, J.M., Liu, P. \& Singleton, A. 2016. Using wavelet tools to analyse seasonal variations from InSAR time-series data: a case study of the Huangtupo landslide. Landslides, 13, 437-450, The final publication is available at Springer via: https://link.springer.com/article/10.1007\%2Fs10346-015-0589-y

reservoir water level. Reservoir water level, which is completely regulated by the dam activity, is mainly in 'anti-phase' with natural rainfall, due to flood control in the Three Gorges project. The seasonal displacements of the Huangtupo landslide is found to be 'in-phase' with respect to reservoir water level and the rainfall towards the front edge of the slope and to rainfall at the higher rear of the slope away from the reservoir.

Keywords: InSAR; wavelet analysis; continuous wavelet transform; cross wavelet transform; wavelet coherence; time-series; time-frequency space; landslide; triggering factors

\section{Introduction}

Rainfall and reservoir water level changes (mainly rapid water level decreases) are vital triggering factors of landslides, playing a crucial role in the landslide dynamics. Water can act in several ways: (a) reducing shear strength of the weak zones due to the physical and chemical interactions between the slip zones' materials and groundwater (He et al. 2008, He et al. 2010, Jiao et al. 2014, Wen and Chen 2007) or due to pore pressure increase (i.e. a rise in pore-water pressure causes a drop in effective stress reducing the shear strength of a slope); (b) increasing the hydraulic gradient and seepage force of a landslide mass during water level lowering (Jiang et al. 2011); (c) reducing soil suction (Bittelli et al. 2012, Cascini et al. 2014); (d) increasing soil unit weight; and/or (e) causing soil consolidation-swelling due to the changes of effective stresses on the landslide mass (Jiang, et al. 2011). However, these water actions are not independent from each other. Shear strength, soil suction and consolidation deformation can be affected by transient seepage forces (Jiang et al., 2011). Many papers have discussed the above-mentioned effects on the Three Gorges landslides (Bin et al. 2007, Cojean and Caï 2011, Du et al. 2013, He, et al. 2008, He, et al. 2010, Hu et al. 2012, Hu et al. 2012, Jiang, et al. 2011, Jin et al. 2012, Wang et al. 2004, Wang et al. 2008, Xia et al. 2013, Xie 2009).

The relationship between likely triggering factors (such as rainfall or reservoir water level changes) and landslide kinematics (i.e. displacements) is a key aspect for understanding landslide behaviour, its mechanism, and the subsequent design and 
This paper has to be cited as: Tomás, R., Li, Z., Lopez-Sanchez, J.M., Liu, P. \& Singleton, A. 2016. Using wavelet tools to analyse seasonal variations from InSAR time-series data: a case study of the Huangtupo landslide. Landslides, 13, 437-450, The final publication is available at Springer via: https://link.springer.com/article/10.1007\%2Fs10346-015-0589-y

adoption of remedial measures. When similarity is suspected between seasonalities of landslide kinematics and triggering factors, this is usually studied through qualitative interpretations or direct correlations between two time-series in the frequency domain, assuming the underlying processes are stationary in time (Grinsted et al. 2004). However, Continuous Wavelet Transforms (CWT) expand time-series records into timefrequency space and can therefore find localized intermittent periodicities (Grinsted, et al. 2004) that affect the landslide kinematics. Additionally, when comparing two timeseries, the Cross Wavelet Transform (XWT) and the Wavelet Coherence (WTC) tools permit the recognition of common power and relative phase in time-frequency space, respectively, along with assessing significant coherence and confidence levels against red noise backgrounds (Torrence and Compo 1998). Consequently, these tools are very useful for exploring seasonal patterns which might have a time-lag between the causeeffect (shown by the phase of the XWT or WTC).

This paper aims to investigate the feasibility of wavelet tools, such as CWT, XWT and WTC, for recognizing localized variations of power within Differential SAR Interferometry (InSAR) time-series. We demonstrate an optimal procedure for its regular application, using the Huangtupo landslide in the Three Gorges area (China), as an example.

The paper is organized as follows: Section 2 briefly defines the CWT concept as well as the XWT and the WTC approaches. The general analysis framework proposed in this paper is detailed in Section 3. Section 4 describes the geological setting of the Huangtupo landslide area. Section 5 explains the available InSAR, rainfall and reservoir water level time series data from the study area. Section 6 analyses the Huangtupo's dataset described in the previous section using CWT, whereas Section 7 shows the application of XWT and WTC. Section 8 discusses the results derived from the previous analyses, and Section 9 summarises the main conclusions of the paper.

\section{Wavelet Tools}

Among all the wavelet transform tools designed to study time patterns in non-stationary processes (Torrence and Compo 1998), the CWT is especially suited to extract features from low signal-to-noise ratio time series. The CWT is useful for analysing individual 
This paper has to be cited as: Tomás, R., Li, Z., Lopez-Sanchez, J.M., Liu, P. \& Singleton, A. 2016. Using wavelet tools to analyse seasonal variations from InSAR time-series data: a case study of the Huangtupo landslide. Landslides, 13, 437-450, The final publication is available at Springer via: https://link.springer.com/article/10.1007\%2Fs10346-015-0589-y

time-series. The result of the CWT is usually represented as a two-dimensional image with two axes defined by the time instants (e.g. dates) and the frequency or period of the time patterns. Therefore, the positions with high values in the 2-D CWT representation indicate the presence of significant time patterns (i.e. periodicities) at particular times or dates (see Figure 4 and related comments in Section 5 for examples of the CWT results).

If the relationship between two different phenomena is of interest, two individual CWT's can be combined by using the XWT or the WTC tools, which are defined and described in detail by Grinsted (2004) This work makes use of all these wavelet tools (CWT, XWT and WTC) which have demonstrated their usefulness in this context (Grinsted, et al. 2004) and for which there are freely available Matlab codes (NOC 2014).

The XWT is computed by multiplying the CWT of one time series by the complex conjugate of the CWT of the second time series. The resulting XWT is a 2-D representation of complex numbers. The absolute value of the XWT will be high in the time-frequency areas where both CWT's display high values, so this helps identify time patterns common in the two data sets. The phase of the XWT indicates the time lag between the two time-series. For instance, it will be 0 when the two time series are coincident in time (i.e. in-phase), whereas it will be around +/- 180 degrees if they are in anti-phase (i.e. one is maximum when the other is minimum and vice versa).

For readers familiar with SAR interferometry, an analogy can be used to understand the meaning of the XWT: it is equivalent to the complex product of two images. The magnitude (absolute value) is high only where both images present high backscatter simultaneously, so the XWT reveals areas in the 2-D time-frequency space (obtained by the CWT) with high common power.

On the other hand, the WTC is defined as the coherence between the two CWT's, measured in the 2-D time-frequency domain. It is computed by the normalised crosscorrelation between them, including a smoothing operator that operates in both domains (time and frequency or scale). In other words, WTC is the result of normalising a smoothed version of the XWT. It is also the equivalent of the complex interferometric coherence in SAR interferometry, but calculated here with the 2-D CWT images instead 
This paper has to be cited as: Tomás, R., Li, Z., Lopez-Sanchez, J.M., Liu, P. \& Singleton, A. 2016. Using wavelet tools to analyse seasonal variations from InSAR time-series data: a case study of the Huangtupo landslide. Landslides, 13, 437-450, The final publication is available at Springer via: https://link.springer.com/article/10.1007\%2Fs10346-015-0589-y

of radar images. As a coherence, its absolute value will be high (i.e. close to 1 ) in those areas of the time-frequency plane in which the time-frequency pattern is locally similar (i.e. coherent) in the two CWT's. In contrast with the XWT, there is no requirement for large values in both the individual CWT's to produce a high coherence, so it is especially useful to detect additional similarities between two data sets. These similarities depend only on the form of the time-frequency pattern itself and not on the power of particular components in the CWT. The interpretation of phase information is the same as for XWT, since they are computed in the same way with the exception of the smoothing operator used in the WTC. Finally, it is important to note that the smoothing operation required for the WTC degrades the resolution of the result in the time-frequency domain. This effect is analogous to the spatial resolution degradation produced by a multi-looking in SAR interferometry.

\begin{tabular}{|c|c|l|l|c|}
\hline $\begin{array}{l}\text { Wavelet } \\
\text { tool }\end{array}$ & $\begin{array}{c}\text { Number of } \\
\text { series analysed }\end{array}$ & Meaning of magnitude & Meaning of phase & $\begin{array}{c}\text { Time-frequency } \\
\text { resolution }\end{array}$ \\
\hline CWT & 1 & Presence of time patterns & \multicolumn{1}{|c|}{ Original } \\
\hline XWT & 2 & $\begin{array}{l}\text { Time patterns with large } \\
\text { power in both time-series }\end{array}$ & $\begin{array}{l}\text { Time lag (delay) } \\
\text { between both time- } \\
\text { series }\end{array}$ & Original \\
\hline WTC & 2 & $\begin{array}{l}\text { Similar time patterns in } \\
\text { both time-series }\end{array}$ & $\begin{array}{l}\text { Time lag (delay) } \\
\text { between both time- } \\
\text { series }\end{array}$ & Degraded \\
\hline
\end{tabular}

Table 1. Summary of features of wavelet tools

Table 1 summarises the main features of the wavelet tools employed in this work. Additional comments on the interpretation of results from these wavelet analysis tools are provided in Section 6.

\section{Sampling strategies}

In this section we describe a systematic methodology for analysing InSAR time-series information from landslides using continuous wavelet tools. The proposed methodology can be used for the identification and study of the time-frequency relationships between triggering factors (e.g. reservoir water level fluctuations, rainfall, piezometric water level, etc.) and surface displacements (e.g. measured by InSAR). 
This paper has to be cited as: Tomás, R., Li, Z., Lopez-Sanchez, J.M., Liu, P. \& Singleton, A. 2016. Using wavelet tools to analyse seasonal variations from InSAR time-series data: a case study of the Huangtupo landslide. Landslides, 13, 437-450, The final publication is available at Springer via: https://link.springer.com/article/10.1007\%2Fs10346-015-0589-y

Firstly, the time-series input data for wavelet analysis must be equally spaced in time, i.e. evenly sampled. However, although SAR satellites have a regular revisit interval (e.g. 35 days for ERS and ENVISAT, 11 days for TerraSAR-X, 46 days for ALOS-PALSAR), some images are usually missing or excluded from processing (because they exhibit a high Doppler centroid, due to technical problems on the satellite or communication system, due to the large baselines of the resulting interferograms, etc.). Consequently, the timeseries data derived from InSAR processing are rarely distributed evenly in time, exhibiting some gaps (Figure 1). This issue can be solved using linearly interpolated values for the missing dates at the expected revisit times $\left(\Delta t_{R}\right)$ (Figure 1$)$. Note that the interpolated values do not introduce false periods because their linear feature produces just a constant or direct current (DC) component in the frequency domain.

Furthermore, computing missing values in this way matches how InSAR time-series are obtained. InSAR processing chains usually compute displacements as the superposition of linear and non-linear terms. In the frequency domain, linear displacements exhibit an infinite period along time, i.e. a DC component. On the other hand, the non-linear component describes the seasonal fluctuations of the displacement, which can exhibit different periods and even changes along time. Consequently, continuous wavelet analyses (i.e. CWT, XWT and WTC) allow the identification and evolution of the cyclical displacements described by the non-linear component of the InSAR time-series and hence their relations with triggering factors. Thus, after interpolating the missing values, linear and non-linear components of displacement can be separated. The linear component is computed by means of a linear least squares fitting, and the non-linear component as the difference between the displacement time-series and the previously calculated linear component. Note that the separation of the linear and non-linear component could have been carried out before the interpolation of the missing values, hence interpolating only the non-linear component. Both approaches produce equivalent results.

Usually, InSAR data present noise due to different reasons (e.g. due to temporal decorrelation, atmospheric artefacts, etc.) that distort the estimation of the phase and is included in the non-linear component of the derived time-series analysed by means of the wavelet tools. Although this noise might not be perfectly random (e.g. due to 
This paper has to be cited as: Tomás, R., Li, Z., Lopez-Sanchez, J.M., Liu, P. \& Singleton, A. 2016. Using wavelet tools to analyse seasonal variations from InSAR time-series data: a case study of the Huangtupo landslide. Landslides, 13, 437-450, The final publication is available at Springer via: https://link.springer.com/article/10.1007\%2Fs10346-015-0589-y

long-wavelength orbital ramps or atmospheric effects), we assume it is random by definition and consequently, it does not provide any signal in the wavelet analysis.

A second issue for the application of XWT and WTC to InSAR time-series is that the timeseries from the triggering factors (e.g. rainfall) usually present a shorter time sampling interval (typically one day) than that available from the InSAR time series. Consequently, the triggering factors time-series must be down-sampled to the revisiting time period $\left(\Delta t_{R}\right)$ of the used satellite (Figure 1). For this task, the values from the triggering factors time-series have been linearly interpolated at the specific acquisition dates of the SAR images and the missing dates at the expected revisit times.

Considering that wavelet analysis performs a time-frequency analysis of the signal, only the identification of cyclic phenomena with time periods equal or higher than the employed time interval $\left(\Delta t_{R}\right)$ is possible.

The CWT of InSAR and triggering factors time series allow the identification of cyclic displacements and the seasonality of triggering factors in the frequency domain, respectively. Additionally, XWT and WTC permit the recognition of the common power and relative phase in time-frequency space, and the significant coherence and confidence levels against red noise back-grounds (Torrence and Compo 1998) of triggering factors and the associated InSAR time series, respectively. 

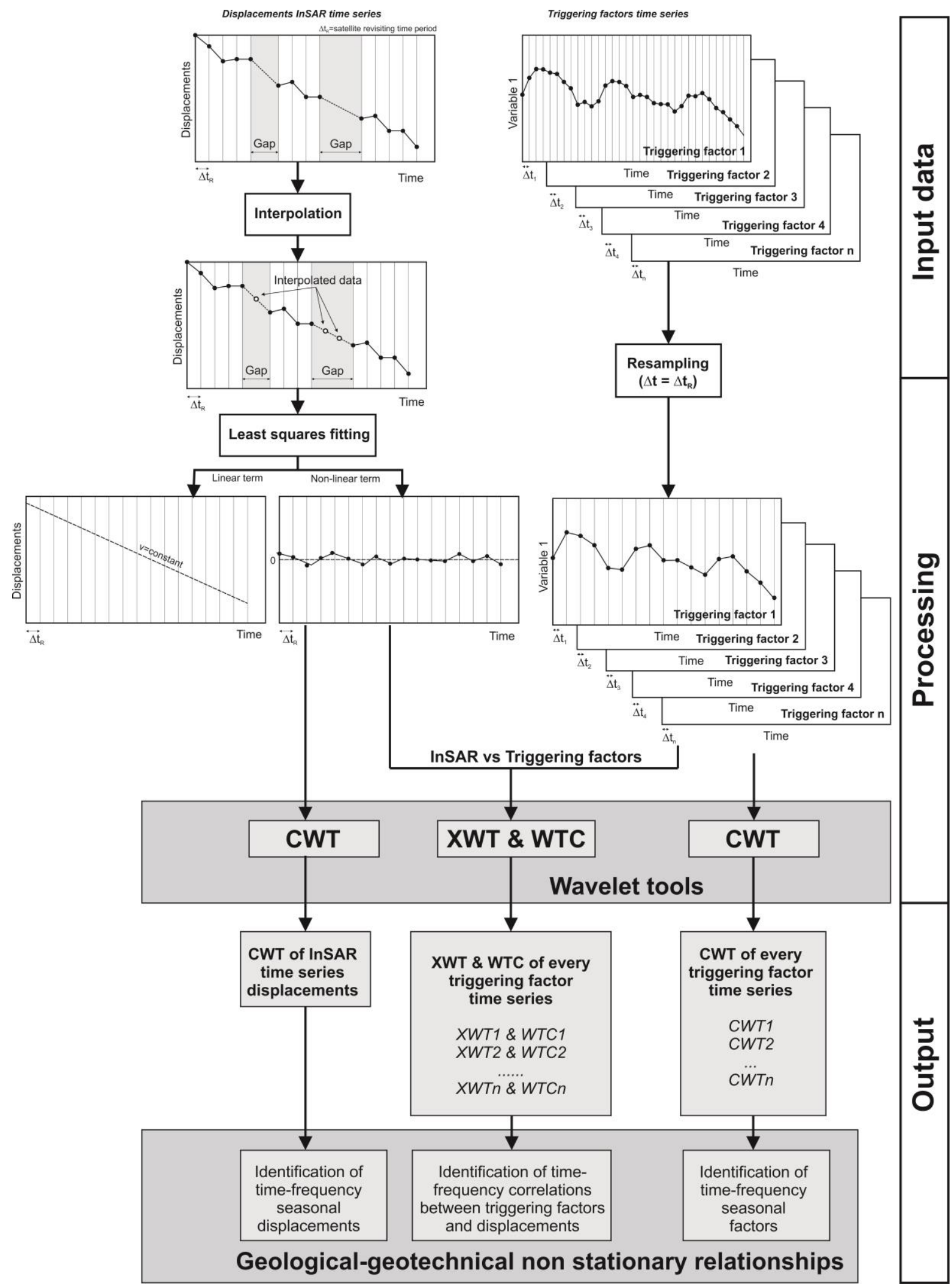

Figure 1. Flow chart of the proposed methodology for the analysis of InSAR time-series using wavelet tools. $v=$ linear displacement. 
This paper has to be cited as: Tomás, R., Li, Z., Lopez-Sanchez, J.M., Liu, P. \& Singleton, A. 2016. Using wavelet tools to analyse seasonal variations from InSAR time-series data: a case study of the Huangtupo landslide. Landslides, 13, 437-450, The final publication is available at Springer via: https://link.springer.com/article/10.1007\%2Fs10346-015-0589-y

\section{Description of the study area}

The Huangtupo slope is one of the largest landslides in the reservoir area of the Three Gorges (TG) Project, with problems related to the residential safety of inhabitants (Deng et al. 2000, Peng et al. 2014). This slope is located upstream from the TG dam and about $1 \mathrm{~km}$ upstream from the old city of Badong, on the southern shore of the Yangtze River in Badong County (Hubei Province, China) (Figure 2). The old town of Badong was moved to this site overlying the Huangtupo slope in 1982 because of the construction of the Gezhouba Dam. The whole slide body extends up to $600 \mathrm{~m}$ a.s.l. from $50 \mathrm{~m}$ a.s.l. (the foot of the landslide is under the river water level) occupying a surface of $1.352 \times 10^{6}$ $\mathrm{m}^{2}$ and having a volume of $6.934 \times 10^{7} \mathrm{~m}^{3}$ (Hu, et al. 2012, Hu, et al. 2012, Xie 2009). The rock basement bedding dips downhill and is affected by an east-west cleavage direction. The upper portion of the rock mass belongs to the middle Triassic rock basement and is composed of purplish red pelite alternating with pelitic siltstone $\left(\mathrm{T}_{2} \mathrm{~b}_{2}\right)$ in the upper area of the slope and grey pelitic limestone $\left(\mathrm{T}_{2} \mathrm{~b}_{3}\right)$ in the middle-lower part of the slope respectively (Figure 3). The landslide body is mostly covered by loose debris (delQ) of variable thickness originating from the degradation and sliding of the original bedrock.

The Huangtupo landslide is a complex deep-seated landslide formed by the superposition of several slumps (Chai et al. 2013, Chen et al. 2008, Hu, et al. 2012, Hu, et al. 2012, Jiang et al. 2007, Tang et al. 2014, Xie 2009) which exhibit "Very slow" to “Extremely slow" velocities (Tomás et al. 2014) according to Cruden and Varnes' (1996) classification .

Four main slumping bodies can be recognized in the slope (Figure 3): Riverside slumping mass I\#, Riverside slumping mass II\#, Garden Spot landslide, and Substation landslide. Riverside slumping mass I\# is located at the northwest side of the slope and Riverside slumping mass II\# is placed northeast of the slope. Both landslides have their toe submerged under the river water level. The third landslide is Garden Spot landslide, which is located southwest of the slope and with a front edge covering the upper part of Riverside slumping mass I\#. Finally, Substation landslide is located southeast of the 
This paper has to be cited as: Tomás, R., Li, Z., Lopez-Sanchez, J.M., Liu, P. \& Singleton, A. 2016. Using wavelet tools to analyse seasonal variations from InSAR time-series data: a case study of the Huangtupo landslide. Landslides, 13, 437-450, The final publication is available at Springer via: https://link.springer.com/article/10.1007\%2Fs10346-015-0589-y

slope and partially placed over Riverside slumping mass II\#. Several more recent smaller landslides can also be recognized in the slope (Figure 3) (Jiang et al., 2007, Chen et al., 2008, Xie, 2009, Hu et al., 2012b, 2012a).

Regarding the Huangtupo landslide, Tomás et al. (2014) concluded that displacements can be explained by the means of a gravitational creep model, only controlled by geological conditions, with superposed minor vertical displacement oscillations related to consolidation-expansion processes caused by groundwater changes induced by the river fluctuations. The rest of the slope (i.e. Riverside Slumping Mass II\#, Substation and Garden Spot landslides) exhibits a stable behaviour with only minor seasonal displacements related with river water level in the lower area and rainfall in the upper area of the slope, respectively.

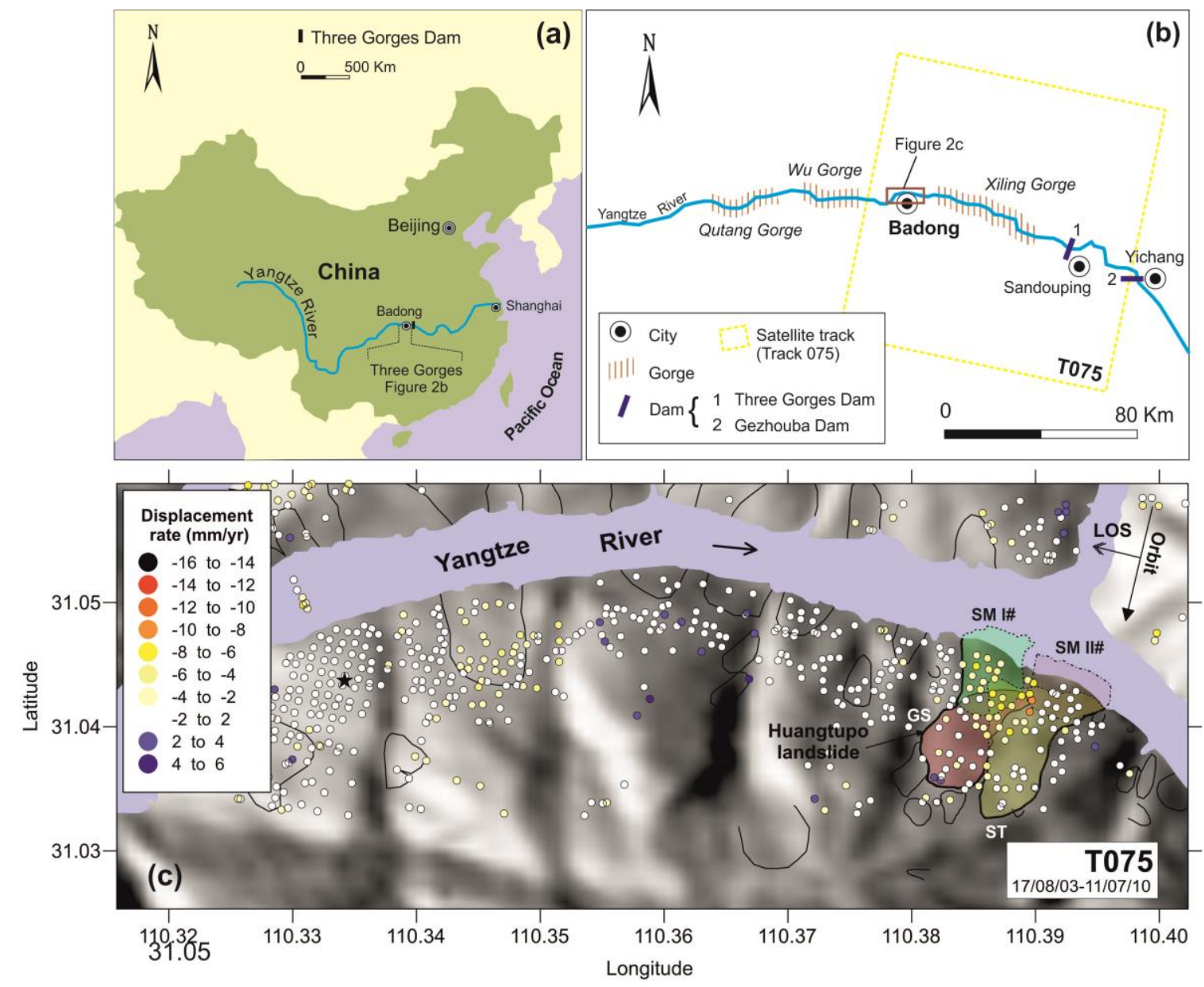

Figure 2. Location of the Huangtupo landslide. InSAR data used for the analysis have been overlaid. The persistent scatterers (PS) used for illustrating the wavelet analysis 
This paper has to be cited as: Tomás, R., Li, Z., Lopez-Sanchez, J.M., Liu, P. \& Singleton, A. 2016. Using wavelet tools to analyse seasonal variations from InSAR time-series data: a case study of the Huangtupo landslide. Landslides, 13, 437-450, The final publication is available at Springer via: https://link.springer.com/article/10.1007\%2Fs10346-015-0589-y

are those contained within the Huangtupo landslide area. The plotted landslide boundaries plotted in (c) are based on the works of Cojean \& Cai (2011) and Chai et al. (2013). The black star represents the reference point (i.e. the point with zero displacement) which has been placed in the area of Badong City Council building. SM I \#, SM II \#, GS and ST are the Slumping Mass I\#, the Slumping Mass II\#, the Garden Spot landslide and the Substation landslide, respectively.
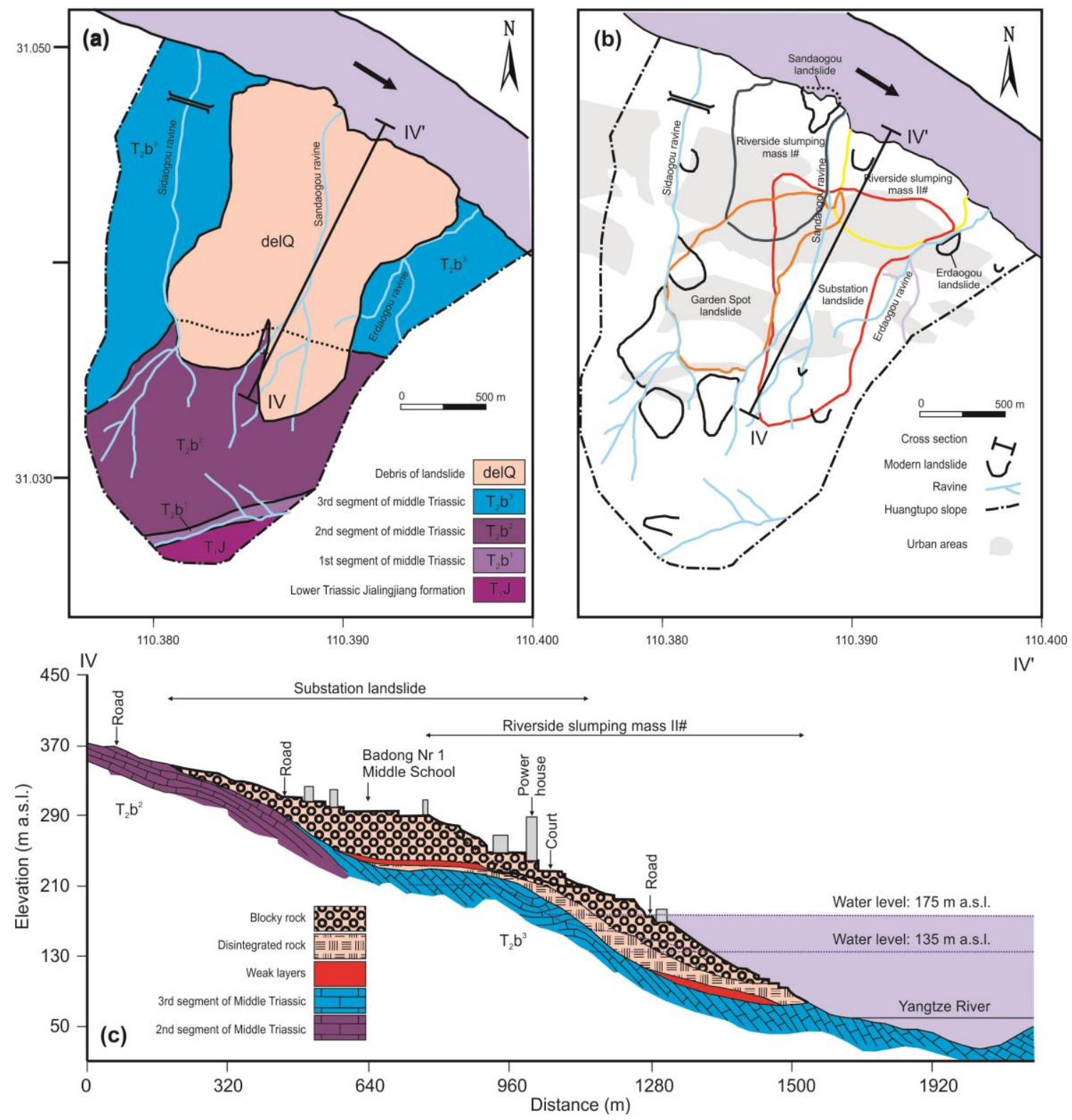

Figure 3. Zonation of the Huangtupo landslide (adapted by Tomás et al. (2014) from (Chai, et al. 2013, Tang et al. 2009, Xie 2009)) 
This paper has to be cited as: Tomás, R., Li, Z., Lopez-Sanchez, J.M., Liu, P. \& Singleton, A. 2016. Using wavelet tools to analyse seasonal variations from InSAR time-series data: a case study of the Huangtupo landslide. Landslides, 13, 437-450, The final publication is available at Springer via: https://link.springer.com/article/10.1007\%2Fs10346-015-0589-y

\section{Data used in this study}

In this work, the suitability of wavelet techniques for the analysis of landslide time-series data derived from InSAR is illustrated using the Huangtupo landslide as a case study. For this landslide, three different time-series have been considered, two of them corresponding to plausible triggering factors (i.e. reservoir water level and rainfall) which are expected to be linked with landslide activities, and the third corresponding to the displacement time-series of the landslide measured by InSAR. Monthly reservoir water level is available between June 2000 and January 2010, exhibiting clear cyclical changes due to flooding control measures. Rainfall data are also available from the meteorological station at Badong with a time-step of 10 days, also displaying a clear seasonality due to monsoons (Figure 4). The InSAR data used in this work were obtained by processing 41 Envisat ASAR images collected between August 2003 and July 2010 from descending track 075 (T075) through a small baseline subset approach (Berardino et al. 2002) developed as part of the StaMPS package (Hooper 2008), and validated by comparing the time-series with in situ measurements (Tomás, et al. 2014). A detailed description of the data processing can be found in Liu et al. (2013) and Tomás et al. (2014).

Following the procedure described in Section 3, the rainfall and the reservoir water level time-series have been resampled using a linear interpolation, to a 35 day interval (Figure 1). This corresponds to the minimum revisiting period for the Envisat ASAR satellite. For those dates in which InSAR displacements are not available, interpolated values have been assigned. Subsequently, the InSAR time-series have been decomposed into linear and non-linear terms by fitting a line by means of a least square method. The non-linear displacements used in the wavelet analysis have been computed as the differences between the original time-series and the fitted line (Figure 1). 
This paper has to be cited as: Tomás, R., Li, Z., Lopez-Sanchez, J.M., Liu, P. \& Singleton, A. 2016. Using wavelet tools to analyse seasonal variations from InSAR time-series data: a case study of the Huangtupo landslide. Landslides, 13, 437-450, The final publication is available at Springer via: https://link.springer.com/article/10.1007\%2Fs10346-015-0589-y

\section{Application of CWT to the Huangtupo landslide}

\subsection{Reservoir water level}

The initial water level of the Yangtze River was $65 \mathrm{~m}$ a.s.l. and the first reservoir impoundment started on 1st June 2003. The reservoir water level reached $135 \mathrm{~m}$ on 15th June 2003 (Figure 4). On 27th October 2006 the water level of the reservoir increased to $156 \mathrm{~m}$ a.s.l. and in November 2008 rose to $175 \mathrm{~m}$ a.s.l. This increase in reservoir water level from June 2003 is affected by seasonal fluctuations that have major impacts on the stability of slopes (Singleton et al., 2014; Tomás et al., 2014). These seasonal fluctuations correspond with amplitudes over 5, 10 and $25 \mathrm{~m}$ for the first, second and third impoundment stages respectively (Figure 4). These water level changes are associated with the reservoir operation at the TG project for flood control, power generation, and navigation, varying widely from 15 to $30 \mathrm{~m}$ over the course of a year and up to several meters within a day (Tullos 2009). Thus, water level was projected to fluctuate in a cycle opposite to natural conditions, with lower levels during the summer and higher levels in the winter (Tullos 2009).

From the analysis of the continuous wavelet power of the reservoir water level (Figure 4, left) we can observe a clear annual (365 days) cycle since 2006, when the water level of the reservoir started increasing to $156 \mathrm{~m}$ a.s.l.

Additionally, a half-year seasonal fluctuation (a burr shaped edge of the thick contour in Figure 4) can be identified from November 2008, when the reservoir water level reached its maximum value. This last seasonality might be related with semi-annual reservoir regulations.

\subsection{Rainfall}

Fang et al. (2010) revealed that the total seasonal rainfall in the TG increases in summer and winter, and decreases in spring and autumn. Additionally, drying changes are more notable in March and September, while wetting trends are greater in January, February, June and July. From the analysis of the Continuous wavelet power of the rainfall timeseries (Figure 4, right) we can observe a clear one-year (365 days) cycle related with the monsoons, along the whole observation period, in Figure 4 (right). 

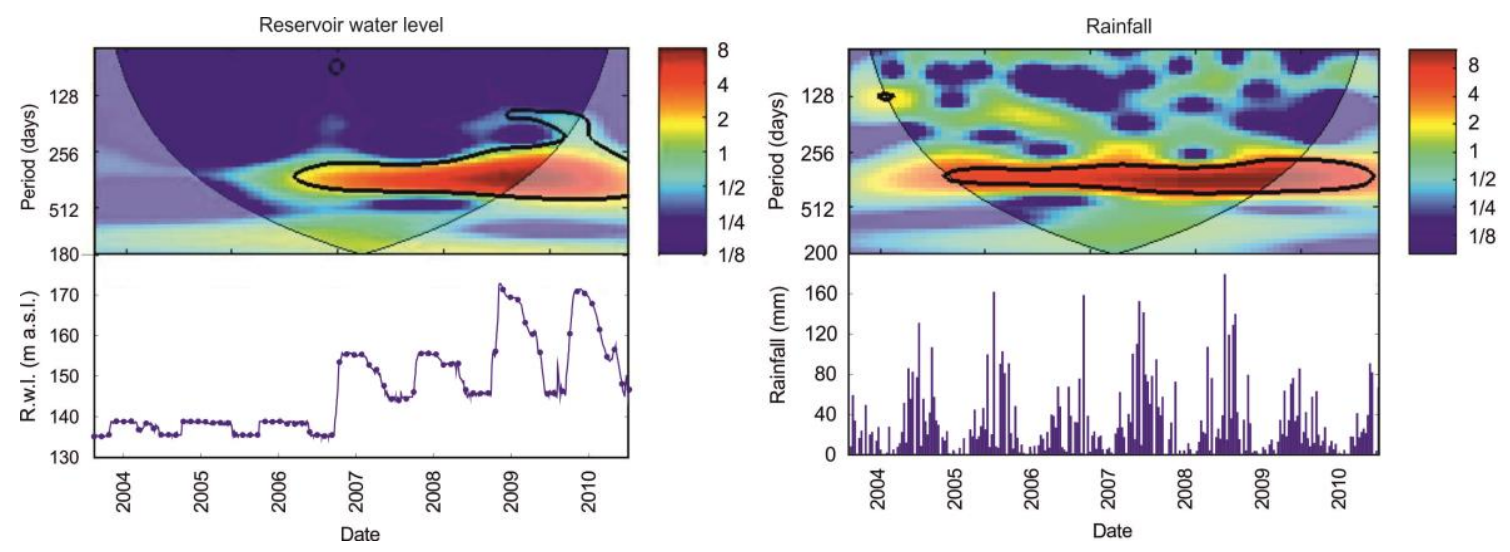

Figure 4. Continuous wavelet power of the reservoir water level (left) and rainfall (right) time series. The thick contour designates the $5 \%$ significant level against red noise. The cone of influence (COI) where edge effects might distort the picture is shown as a lighter shadow. Points in left figure correspond to equally-spaced (35 days) interpolated data used for the analysis.

\subsection{Deformation time-series data}

The third time-series we have analysed consists of the InSAR displacement time-series derived from the processing explained in Section 3. For this purpose, the mean timeseries (i.e. the averaged values on the displacements for the different dates), from the four main landslides (i.e. those described in section 3: Riverside slumping mass I\#, Riverside slumping mass I\#, Garden Spot landslide and Substation landslide) have been analysed. The reasons why the CWT from the four landslides have been computed separately is that different kinematics and relationships between the displacements and triggering factors were recognized by Tomás et al. (2014) in a qualitative way. Note that, for illustrating the usefulness of wavelet tools, in this work we have averaged the nonlinear term of the time-series from all points within each mass movement because they exhibit a very similar seasonal trends and then we have considered the average timeseries as representative of the kinematics of each landslide as a whole.

From the analysis of the CWT of the InSAR time-series (Figure 5) we can observe a oneyear cycle (365 days period) along the whole observation interval for the four main landslides, although it is less evident for Garden Spot than for the other three slides. This 
This paper has to be cited as: Tomás, R., Li, Z., Lopez-Sanchez, J.M., Liu, P. \& Singleton, A. 2016. Using wavelet tools to analyse seasonal variations from InSAR time-series data: a case study of the Huangtupo landslide. Landslides, 13, 437-450, The final publication is available at Springer via: https://link.springer.com/article/10.1007\%2Fs10346-015-0589-y

means that the displacements measured by InSAR exhibit cyclic displacements which can be related with seasonal rainfall episodes or reservoir water level changes. Additionally, some power signals with a period of 3 to 4 months and a significant level against red noise can be recognized during the time intervals 2004-05 and 2007-08. Although this signal seems to be related to the response of the ground surface to seasonal variations of rainfalls, the cause of this relationship needs further research to be confirmed.

The cross analysis of displacements and triggering factors using XWT and WTC will help confirm the role of rainfall episodes and reservoir water level changes on the Huangtupo landslide kinematics.
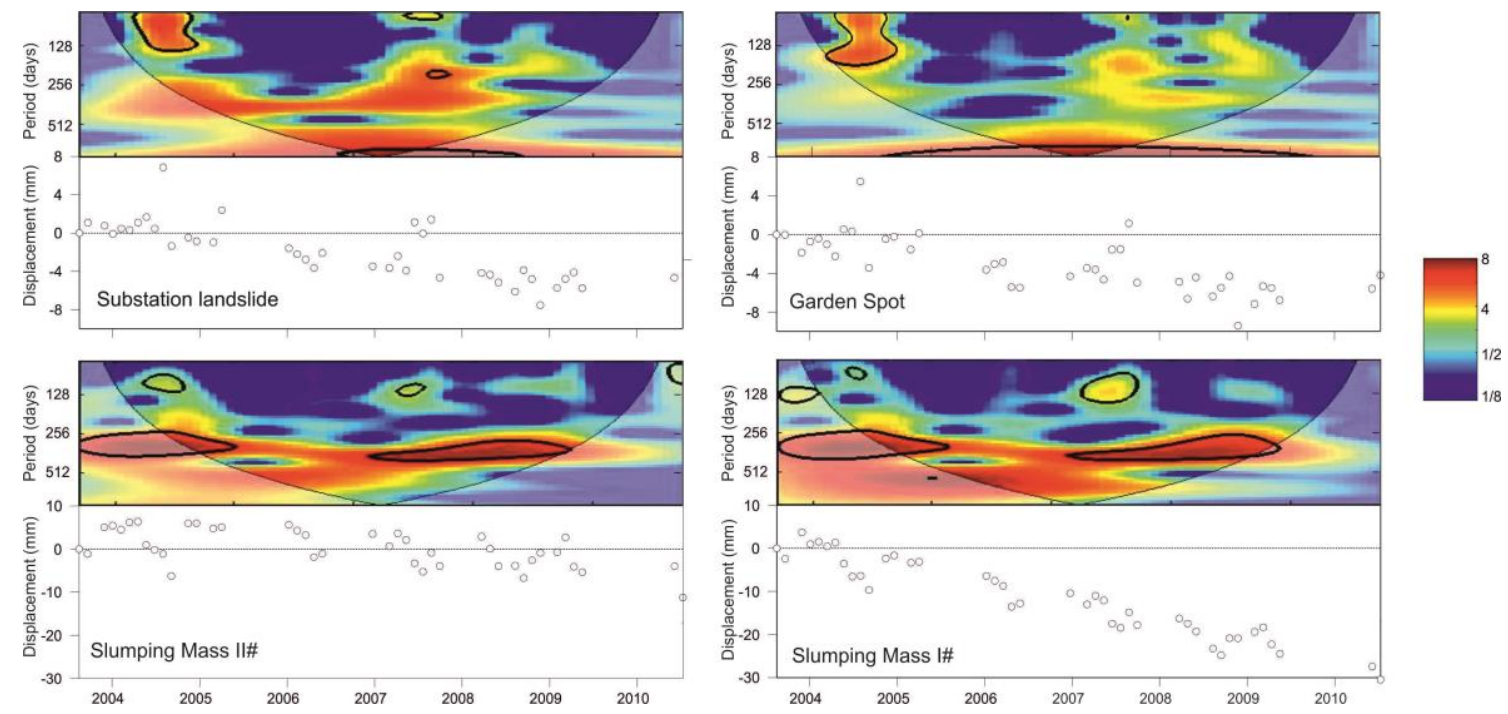

Figure 5. Continuous wavelet transform of the mean InSAR displacements in the Line of Sight (LOS) for the different slumping masses from the Huangtupo landslide (see Figure 3 for landslides zonation). The thick contour designates the $5 \%$ significant level against red noise. The cone of influence (COI) where edge effects might distort the picture is shown as a lighter shadow. 
This paper has to be cited as: Tomás, R., Li, Z., Lopez-Sanchez, J.M., Liu, P. \& Singleton, A. 2016. Using wavelet tools to analyse seasonal variations from InSAR time-series data: a case study of the Huangtupo landslide. Landslides, 13, 437-450, The final publication is available at Springer via: https://link.springer.com/article/10.1007\%2Fs10346-015-0589-y

\section{Application of XWT and WTC to the Huangtupo landslide}

\subsection{XWT and WTC of rainfall and reservoir water level}

Figure 6 shows the XWT and WTC of reservoir water level and rainfall in Badong County. Both figures show a high common power between reservoir water level and rainfall time-series approximately in the 365 days (1 year) period for the whole study period (2004-09). The XWT and the WTC also shows that rainfall and reservoir water level are in anti-phase (i.e. a phase shift of $180^{\circ}$ ) in all the sectors with significant common power, as can be easily recognized in the lower plot from Figure 6, in agreement with one of the objectives of the TG project mentioned in Section 5, which consists on the fluctuation of the water level in a cycle (i.e. 365 days) opposite to natural conditions (Tullos, 2009) mainly for flood control.

\subsection{XWT and WTC of rainfall and the landslide displacement}

Because rainfall is a well-known triggering factor of landslides (Bittelli, et al. 2012, He, et al. 2008, He, et al. 2010, Jiang, et al. 2011, Jiao, et al. 2014, Wen and Chen 2007), (Jiang, et al. 2011), this section assesses the relationship between rainfall and the Huangtupo slope displacements through XWT and WTC analysis. The plots for the four different slumping masses are shown in Figure 7. As expected, a high significant power is found for a 365-day period for the four landslides, practically for the whole studied period. Note that rainfall and displacements are in-phase at Substation and Garden Spot landslides during the whole period. This fact was described by Xie (2009) and Tomás et al. (2014). However, Riverside Slumping Mass I\# and II\# show a predominantly antiphase relationship with rainfall with a period of 365 days ( 1 year).

Additionally, a common power with a period varying from 180 to 30 days (6 to 1 months) can be observed for the four landslides during 2008-2009, coinciding with the period in which the maximum reservoir water level was reached for the first time (Figure 8). Note that this relationship is in-phase for the lower landslides (i.e. slumping Mass \#I and \#II) and in antiphase with the others (i.e. Substation and Garden Spot landslides). 


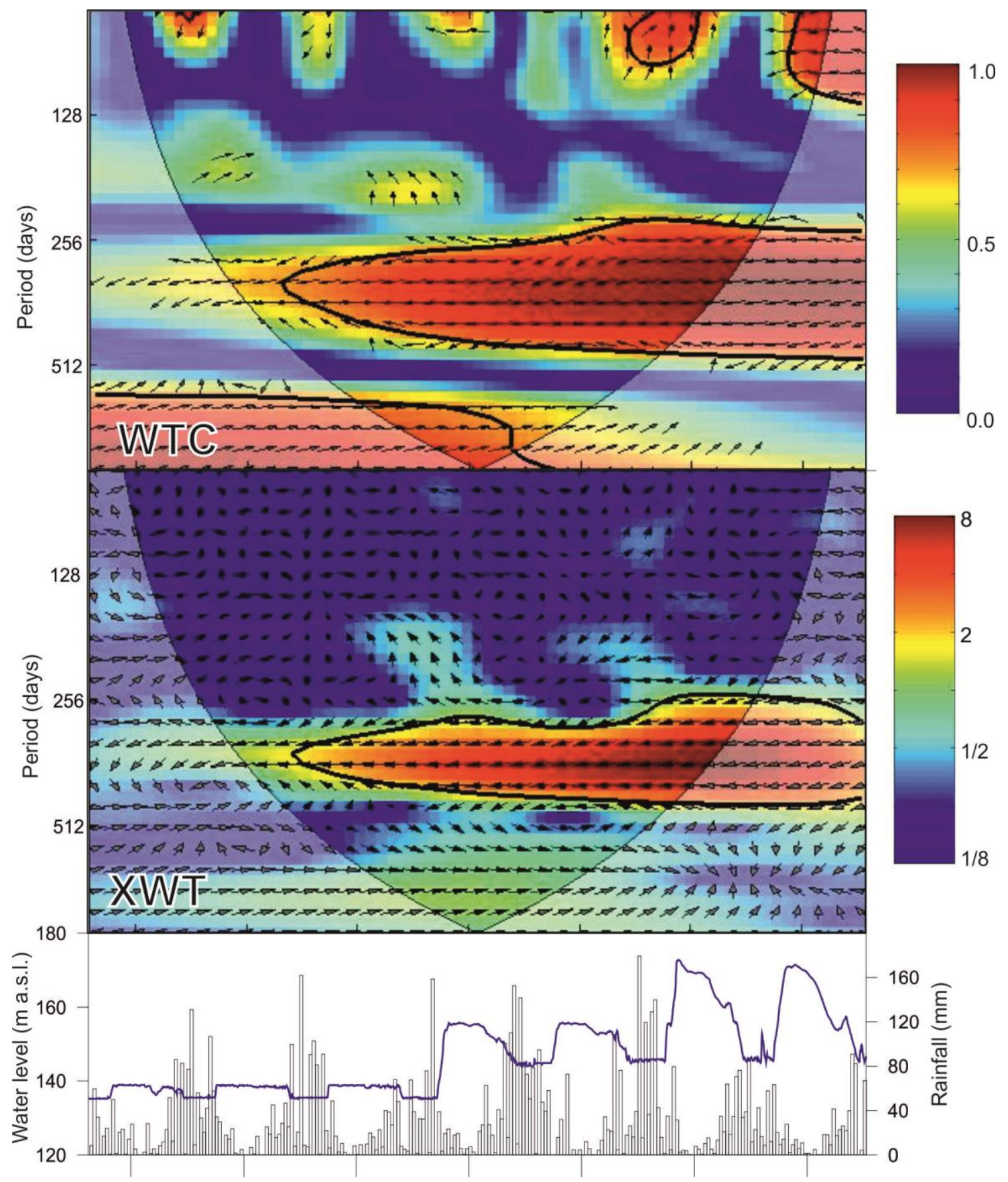

Figure 6. Cross wavelet transform and wavelet coherence of reservoir water level and rainfall in Badong county. The relative phase relationship is shown as arrows, with inphase pointing right and anti-phase pointing left and the water level leading displacement by 900 pointing straight down. 
This paper has to be cited as: Tomás, R., Li, Z., Lopez-Sanchez, J.M., Liu, P. \& Singleton, A. 2016. Using wavelet tools to analyse seasonal variations from InSAR time-series data: a case study of the Huangtupo landslide. Landslides, 13, 437-450, The final publication is available at Springer via: https://link.springer.com/article/10.1007\%2Fs10346-015-0589-y
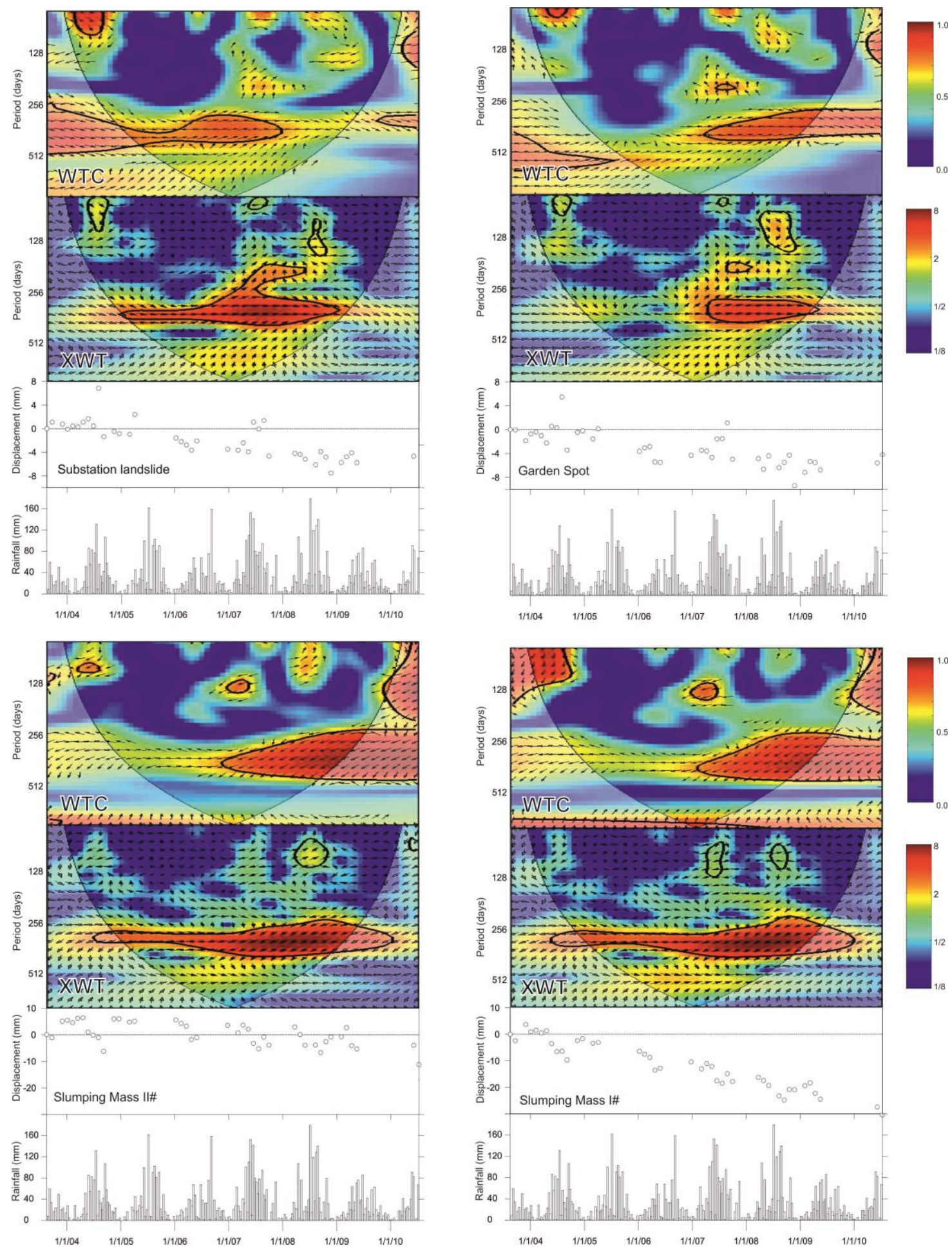

Figure 7. Cross wavelet transform and wavelet coherence of the mean InSAR displacements in the LOS and rainfall for the different parts of the Huangtupo landslide (see Figure 3 for landslides zonation). The relative phase relationship is shown as arrows (with in phase pointing right and anti-phase pointing left and the water level leading displacement by 900 pointing straight down). 
This paper has to be cited as: Tomás, R., Li, Z., Lopez-Sanchez, J.M., Liu, P. \& Singleton, A. 2016. Using wavelet tools to analyse seasonal variations from InSAR time-series data: a case study of the Huangtupo landslide. Landslides, 13, 437-450, The final publication is available at Springer via: https://link.springer.com/article/10.1007\%2Fs10346-015-0589-y

\subsection{XWT and WTC of reservoir water level and the landslide displacements}

In this section the relationship between reservoir water level and the Huangtupo slope displacements is studied through XWT and WTC analysis. The plots for the four different slumping masses are shown in Figure 8 . In the four plots, a high significant power is recognized for a 365-day period. For Substation and Garden Spot landslides the relation between both variables seems to be near to antiphase.

Riverside Slumping Mass I\# and II\#, which due to their location on the riverside are expected to be highly affected by the river water level, show a clear in-phase relationship indicating that both the landslides displacement and the reservoir groundwater level are in phase, in agreement with Xie (2009), Tomás et al. (2014) and Tang et al. (2014).

\section{Discussion}

In this paper, the relationships between InSAR derived seasonal displacements, reservoir water level and rainfall time-series have been studied using three different wavelet tools. The first wavelet tool is CWT which expands the time-series into a timefrequency space to recognize the oscillations of the variables in an intuitive way (Grinsted, et al. 2004). This analysis has allowed the identification of a common annual seasonality in the three analysed time-series from Huangtupo (i.e. the reservoir water level, the rainfall and the landslide displacement). The seasonality observed in the rainfall time-series and the associated CWT (Figure 4) can be explained by the subtropical highly seasonal monsoon climate of the study area, characterized by annual total rainfall higher than $1000 \mathrm{~mm}$ mainly concentrated in summer and winter (Fang, Hang and Xinyi 2010). Thus, the reservoir water level is regulated according to the above described rainfall seasons (Tullos 2009). This reservoir water level regulation induces a clear seasonality also observed in the time-series and the CWT shown in Figure 4 that can be explained considering the reservoir operation cycles (Wang et al. 2013): a) Firstly, the water level is maintained at its lowest level during the monsoon seasons (i.e. June, July, and August) in order to prevent catastrophic floods, as those occurred in 1911, $1931,1935,1954,1981$ and 1998 that caused the death of hundred thousands of people and the displacement of millions of people (Jackson and Sleigh 2000). b) Later, the reservoir impoundment begins at the end of the wet season in September to the 
This paper has to be cited as: Tomás, R., Li, Z., Lopez-Sanchez, J.M., Liu, P. \& Singleton, A. 2016. Using wavelet tools to analyse seasonal variations from InSAR time-series data: a case study of the Huangtupo landslide. Landslides, 13, 437-450, The final publication is available at Springer via: https://link.springer.com/article/10.1007\%2Fs10346-015-0589-y

maximum level, which is maintained from November to February for power generation and navigation. c) Finally, the reservoir water level is gradually decreased to the minimum previous level during spring, mainly for downstream irrigation. Consequently, the landslide kinematics are highly conditioned by this rainfall and reservoir water level seasonality, which induces important changes in the reservoir slopes groundwater levels causing different unfavourable effects. These changes modify the equilibrium conditions of the slope introducing a cyclicity in the landslide displacements' time-series that can be recognized in the CWT of the mean InSAR landslides displacements shown in Figure 5.

Therefore, the CWT of the three considered time-series allows periodicities to be identified in the InSAR time series without assessing the relationship between different time-series. This task has been performed by means of the wavelet tools XWT and WTC, which identify the common power and the relative phase in time-frequency space, and allow the significant coherence between two time-series to be found. This analysis has been performed comparing the three available time-series. The comparison between rainfall and reservoir water level (Figure 6) has confirmed the anti-phase relationship, with a one year period, between both variables. This fact agrees with the purpose of the TG project (Tullos 2009) for flood control during most of the monsoon seasons (i.e. the most raining period) by means of the increase of the reservoir capacity by lowering the water level. In addition, the computation of the XWT and WTC spectra (Figure 8) have also proved that the displacements from the slumping masses from Huangtupo located near the Yangtze river shores (i.e. Riverside Slumping Masses I\# and II\#) exhibit annual seasonal displacement kinematics and are mainly in phase with the river water level changes, which seasonally modify the groundwater regime of the near part of the slope, in agreement to the observations performed by other authors (Tang, et al. 2014, Tomás, et al. 2014, Xie 2009). Additionally, this analysis has shown that the displacements from areas from the Huangtupo slope with a higher elevation (i.e. Substation and Garden Spot landslides) are in-phase with rainfall (Figure 7) with a one year cycle, although the gradual filling of the reservoir seems to have a higher effect on the kinematic of the landslide since the reservoir water level reached $156 \mathrm{~m}$ a.s.l., probably due to the 
This paper has to be cited as: Tomás, R., Li, Z., Lopez-Sanchez, J.M., Liu, P. \& Singleton, A. 2016. Using wavelet tools to analyse seasonal variations from InSAR time-series data: a case study of the Huangtupo landslide. Landslides, 13, 437-450, The final publication is available at Springer via: https://link.springer.com/article/10.1007\%2Fs10346-015-0589-y

elevation of the groundwater level on the slope affecting areas which were previously undisturbed by the reservoir water level (Tomás, et al. 2014, Xie 2009).
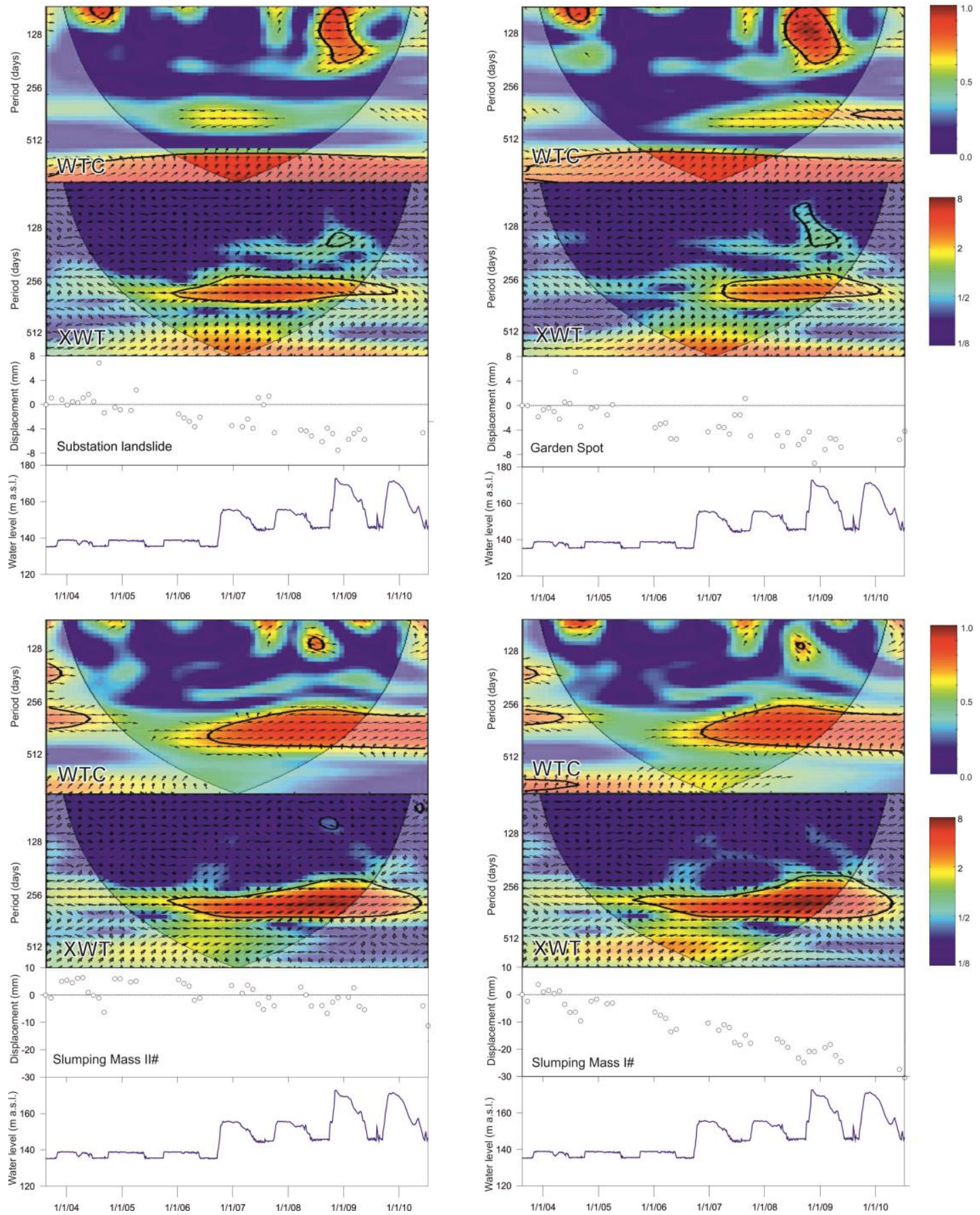

Figure 8. Cross wavelet transform and wavelet coherence of mean InSAR displacements along LOS and reservoir water level for the different parts of the Huangtupo landslide (see Figure 3 for landslides zonation). The relative phase relationship is shown as arrows (with in phase pointing right and anti-phase pointing left and the water level leading displacement by 900 pointing straight down). 
This paper has to be cited as: Tomás, R., Li, Z., Lopez-Sanchez, J.M., Liu, P. \& Singleton, A. 2016. Using wavelet tools to analyse seasonal variations from InSAR time-series data: a case study of the Huangtupo landslide. Landslides, 13, 437-450, The final publication is available at Springer via: https://link.springer.com/article/10.1007\%2Fs10346-015-0589-y

Considering the LOS azimuth (N283.3으 $)$ and the look angle $(\approx 23 \%)$ of the track T075, and the NW-SE Huangtupo slope strike (Figure 2) we can see that this track is more sensitive to vertical displacements than to SW-NE movements. Bearing in mind this fact and the relationships found through wavelet tools, we propose the conceptual model of possible mechanisms for the Huangtupo landslide shown in Figure 9 that illustrates the described in-phase relationship between reservoir water level and Slumping Masses I\# and II\# (Figures 8 and 9). This means that, when the reservoir water level cyclically decreases and increases, it changes the groundwater level and the slope ground surface suffers subsidence accompanied by downslope movement and uplift, respectively, superimposed to the general linear displacement trend subtracted for the wavelet analysis. In the same part of the landslide, rainfall and displacements are in antiphase (Figures 7 and 9) and then subsidence occurs when accumulated rainfall increases, contributing to the elevation of the groundwater level jointly with the reservoir water level reducing the safety factor of the slope. Nevertheless, the non-linear seasonal displacements at Substation and Garden Spot landslides are in phase with rainfall and in antiphase with reservoir water level, as illustrated in Figure 9 and shown in Figures 7 and 8 . This relationship can be interpreted as for higher elevations, since groundwater level is mainly controlled by rainfall and independent from reservoir water level changes (except for the lower part of these landslides), and therefore reservoir water level has a limited influence on the displacement patterns of these landslides. In addition to the mentioned relationships between the non-linear seasonal relationships, Figures 5 shows that the general trend (linear component) of Substation and Garden Spot landslides is much lower than for Slumping Masses I\# and II\# (Figure 5). Therefore, we can conclude that the northwest zone of the Huagtupo slope (i.e. Slumping Mass I\#) exhibits the maximum displacements with superimposed 1-year cycles related with rainfall and reservoir water level. The other main landslides present a more stable behaviour with superimposed seasonal movements related with the rainfall for Garden Spot and Substation landslides and with both rainfall and reservoir water level for Slumping Mass I\#. 
This paper has to be cited as: Tomás, R., Li, Z., Lopez-Sanchez, J.M., Liu, P. \& Singleton, A. 2016. Using wavelet tools to analyse seasonal variations from InSAR time-series data: a case study of the Huangtupo landslide. Landslides, 13, 437-450, The final publication is available at Springer via: https://link.springer.com/article/10.1007\%2Fs10346-015-0589-y

Summarizing, in this work, wavelet tools have confirmed the former proposed relationships between triggering factors and InSAR displacements from the Huangtupo landslide, providing a more objective quantification of the processes and allowing the identification of gradual temporal changes in the cause-effect relations.

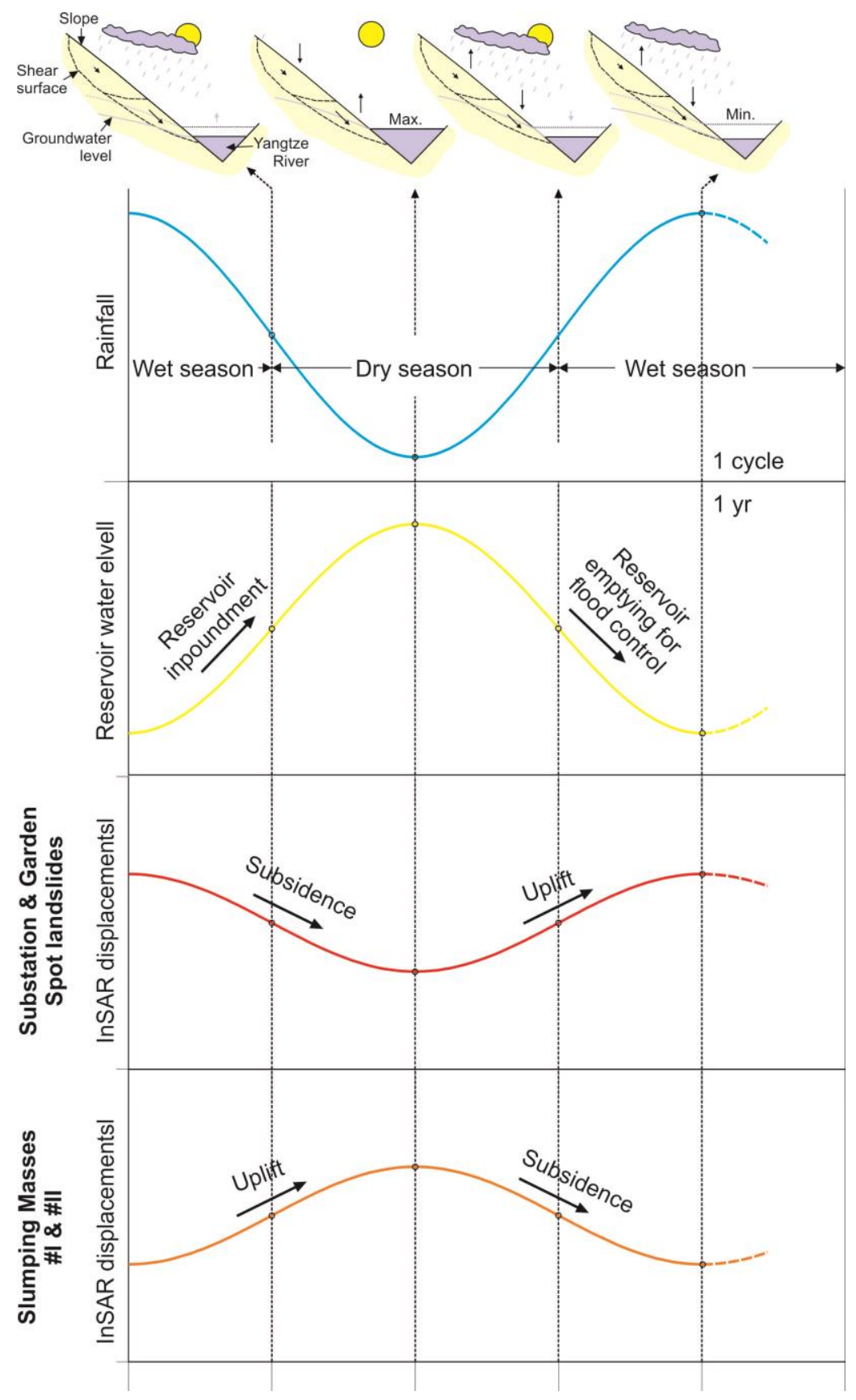

Figure 9. Conceptual model of mechanisms for the Huangtupo landslide based on wavelet analysis results of the non-linear component of InSAR time-series. Vertical axes are non-scaled. 
This paper has to be cited as: Tomás, R., Li, Z., Lopez-Sanchez, J.M., Liu, P. \& Singleton, A. 2016. Using wavelet tools to analyse seasonal variations from InSAR time-series data: a case study of the Huangtupo landslide. Landslides, 13, 437-450, The final publication is available at Springer via: https://link.springer.com/article/10.1007\%2Fs10346-015-0589-y

These tools present some advantages and drawbacks, which are described below. In general, we can conclude that the main advantages of using wavelet tools for landslides' time series analysis are as follows. a) The methodology is simple and free of model selection parameters (i.e. we do not have to make assumptions concerning the data for the time-series under investigation) (Gençay et al. 2001) and can be applied using different available toolboxes. b) The CWT allows the analysis of localized variations of power within an InSAR time series of a landslide to determine both the modes of variability and how these modes vary in time, even for nonstationarity in time series (i.e. systems with short-lived transient components), and reveals features we could not see otherwise (Cazelles et al. 2008). This is the key advantage of the wavelet techniques over the more classic approaches which assume stationarity, and thus they are more suitable for landslide time-series research than Fourier methods as the landslide kinematics depends strongly on the time variability of the triggering factors (e.g. rainfall or reservoir water level). c) The WTC and XWT allow the identification of common power and similar patterns regions between the InSAR displacement time-series and the triggering factors, providing very useful information about the time lag between triggering factors and landslide displacements. This information can be exploited by researchers for stating causal relationships and improving landslide models. The main shortcomings regarding the application of wavelet tools for landslide InSAR time-series include: a) The data have to be equally-spaced in time (regular sampling). Although InSAR presents a constant revisiting period, it is not always possible for InSAR time-series to provide a constant time interval as it is usual the loss or exclusion of some images from processing. This fact implies a loss of information for which we have proposed a strategy to enable the application of wavelet techniques. b) Wavelet tools cause an edge effect at the beginning and at the end of the time-frequency space (cone of influence) that is impossible to eliminate and for which the spectral information of the landslide timeseries is less accurate. c) Wavelet tools do not provide information about the underlying mechanisms (Cazelles, et al. 2008) causing the cyclic landslide displacements measured by InSAR time-series. Consequently, further information and analysis is necessary to 
This paper has to be cited as: Tomás, R., Li, Z., Lopez-Sanchez, J.M., Liu, P. \& Singleton, A. 2016. Using wavelet tools to analyse seasonal variations from InSAR time-series data: a case study of the Huangtupo landslide. Landslides, 13, 437-450, The final publication is available at Springer via: https://link.springer.com/article/10.1007\%2Fs10346-015-0589-y

clarify the mechanisms that underlie the mutual relationships and the phase dependence between landslides and triggering factors.

The application of wavelet techniques to time-series obtained from other sensors with a lower revisiting period (e.g. TerraSAR-X which acquires images every 11 days or ground-based SAR systems) would allow lower-period oscillations and correlations to be identified. Additionally, this methodology can be used to explore InSAR displacement time-series corresponding to other phenomena which exhibit non-stationary behaviours, such as land subsidence.

\section{Conclusions}

In this work, a procedure for applying wavelet tools to landslides has been successfully demonstrated. The use of continuous wavelet transform, cross wavelet transform and wavelet coherence tools for analysing relationships between seasonal displacements time-series obtained by InSAR and triggering factors (e.g. rainfall and reservoir water level time-series) on landslides is shown. For this purpose, the available InSAR derived displacement time-series from the Huangtupo landslide, one of the largest landslides in the Three Gorges region, have been used as an example. For applying wavelet tools, InSAR data have been resampled to a constant time step of 35 days, which corresponds to the revisiting period of the InSAR time-series. Subsequently, the InSAR displacement data have been separated into linear and non-linear displacement components. Continuous Wavelet Transform analysis is only performed over the nonlinear component of the InSAR time series. Additionally, Cross Wavelet Transform and the Wavelet Coherence can be performed for different triggering factors of a landslide, also using the non-linear term of the InSAR time-series.

In the analysed case study, one displacement time-series has been considered for each one of the four main slumping masses recognized in the Huangtupo slope, computed by averaging all the persistent scatterers contained within the slide. Subsequently, the CWT has been computed for all time-series, analysing them into time-frequency space, recognizing a predominant annual seasonality, as expected. Similarly, XWT and WTC tools have been applied to find the common power and relative phase in time-frequency 
This paper has to be cited as: Tomás, R., Li, Z., Lopez-Sanchez, J.M., Liu, P. \& Singleton, A. 2016. Using wavelet tools to analyse seasonal variations from InSAR time-series data: a case study of the Huangtupo landslide. Landslides, 13, 437-450, The final publication is available at Springer via: https://link.springer.com/article/10.1007\%2Fs10346-015-0589-y

space between the different analysed time-series. This analysis has confirmed that the seasonal displacements from the lowest areas of the Huangtupo slope (riverside Slumping Masses I \# and II\#) are correlated with reservoir water level, exhibiting annual in-phase seasonality. However, the analysis of the XWT and WTC from the highest elevated areas of the slope (i.e. Substation and Garden Spot landslides) show that these zones are mainly in-phase with annual rainfall.

In brief, the joint analysis of the InSAR time-series and the information extracted from the wavelet analysis has helped state that Riverside Slumping Mass I\# slope presents the higher absolute displacements with superimposed minor seasonal displacements caused by groundwater changes induced by reservoir water level and rainfall. Slumping Mass II\# exhibits a more general stable behaviour with minor cyclic displacements caused by rainfall and reservoir water level. Finally, Substation and Garden Spot landslides display a quite stable behaviour with only seasonal displacements related with rainfall.

This work illustrates the benefits of using wavelet tools for the analyses of individual time-series in both time and frequency, and to find common power and the information about the phase relationship between two time-series. Specifically, the analysed case study highlights the potential of wavelet tools for interpreting InSAR time-series in a quantitative way to better understand displacement oscillations in the frequency space with other variables to find physical phase relationships.

To summarize, the application of wavelet tools (WTC, XWT and WTC) to InSAR and triggering factors time series have helped understand the seasonal kinematic behaviour of the Huagtupo landslide and to recognize the relationships between InSAR displacements and various triggering factors.

\section{Acknowledgements}

R. Tomás was supported by the Generalitat Valenciana fellowship BEST-2011/225 and by the Ministry of Education, Culture and Sport trough the project PRX14/00100. Part of this work is also supported by the Spanish Ministry of Economy and Competitiveness and EU FEDER funds under project TEC2011-28201-C02-02, by the Natural 
This paper has to be cited as: Tomás, R., Li, Z., Lopez-Sanchez, J.M., Liu, P. \& Singleton, A. 2016. Using wavelet tools to analyse seasonal variations from InSAR time-series data: a case study of the Huangtupo landslide. Landslides, 13, 437-450, The final publication is available at Springer via: https://link.springer.com/article/10.1007\%2Fs10346-015-0589-y

Environmental Research Council (NERC) through the GAS and LICS projects (Ref: NE/H001085/1 and NE/K010794/1 respectively) as well as the ESA-MOST DRAGON-3 projects (Ref: 10607 and 10665). We thank JPL/Caltech for the use of ROI_PAC, TU-Delft for DORIS and Andy Hooper for StaMPS in our data processing and analysis. Authors also acknowledge A. Grindsted, J.C. Moore and S. Jevrejeva for the MatLab package for CWT, XWT and WTC analysis, two anonymous reviewers and F. Raspini (University of Florence) for their constructive suggestions and comments, which have been carefully incorporated into the revised manuscript.

\section{References}

Berardino P, Fornaro G, Lanari R and Sansosti E (2002) A new algorithm for surface deformation monitoring based on small baseline differential sar interferograms. Geoscience and Remote Sensing, IEEE Transactions on 40: 2375-2383. doi: 10.1109/tgrs.2002.803792

Bin W, Huiming T, Jiebin Z, Wei X and Jun L (2007) Deformation and failure mechanisms of reservoir landslide considering fluid-solid coupling effect. Chinese Journal of Rock Mechanics and Engineering 26: 4484-4489.

Bittelli M, Valentino R, Salvatorelli F and Rossi Pisa P (2012) Monitoring soil-water and displacement conditions leading to landslide occurrence in partially saturated clays. Geomorphology 173-174: 161-173. doi: http://dx.doi.org/10.1016/j.geomorph.2012.06.006

Cascini L, Sorbino G, Cuomo S and Ferlisi S (2014) Seasonal effects of rainfall on the shallow pyroclastic deposits of the campania region (southern italy). Landslides 11: 779-792. doi: 10.1007/s10346-013-0395-3

Cazelles B, Chavez M, Berteaux D, Ménard F, Vik J, Jenouvrier S and Stenseth N (2008) Wavelet analysis of ecological time series. Oecologia 156: 287-304. doi: 10.1007/s00442-008-0993-2

Cojean R and Caï Y (2011) Analysis and modeling of slope stability in the three-gorges dam reservoir (china) - the case of huangtupo landslide. Journal of Mountain Science 8: 166-175. doi: 10.1007/s11629-011-2100-0

Cruden DM and Varnes DJ (1996) Landslide types and processes. In: Turner AK and Schuster RL (eds) Landslides: Investigation and mitigation (special report), National Research Council, Transportation and Research Board Special Report, Washington, DC, USA, pp 36-75

Chai B, Yin K, Du J and Xiao L (2013) Correlation between incompetent beds and slope deformation at badong town in the three gorges reservoir, china. Environmental Earth Sciences 69: 209-223. doi: 10.1007/s12665-012-1948-9

Chen S, Chen G-J and XU G-L (2008) Mechanism of geological processes of formation and deformation of the huangtupo landslide. Earth Science-Journal of China University of Geoscience 33: 411.

Deng QL, Zhu ZY, Cui ZQ and Wang XP (2000) Mass rock creep and landsliding on the huangtupo slope in the reservoir area of the three gorges project, yangtze river, china. Engineering Geology 58: 67-83.

Du J, Yin K and Lacasse S (2013) Displacement prediction in colluvial landslides, three gorges reservoir, china. Landslides 10: 203-218. doi: 10.1007/s10346-012-0326-8 
This paper has to be cited as: Tomás, R., Li, Z., Lopez-Sanchez, J.M., Liu, P. \& Singleton, A. 2016. Using wavelet tools to analyse seasonal variations from InSAR time-series data: a case study of the Huangtupo landslide. Landslides, 13, 437-450, The final publication is available at Springer via: https://link.springer.com/article/10.1007\%2Fs10346-015-0589-y

Fang Z, Hang D and Xinyi Z (2010) Rainfall regime in three gorges area in china and the control factors. International Journal of Climatology 30: 1396-1406. doi: 10.1002/joc.1978

Gençay R, Selçuk F and Whitcher B (2001) Differentiating intraday seasonalities through wavelet multi-scaling. Physica A: Statistical Mechanics and its Applications 289: 543-556. doi: http://dx.doi.org/10.1016/S0378-4371(00)00463-5

Grinsted A, Moore JC and Jevrejeva S (2004) Application of the cross wavelet transform and wavelet coherence to geophysical time series. Nonlin Processes Geophys 11: 6.

He K, Li X, Yan X and Guo D (2008) The landslides in the three gorges reservoir region, china and the effects of water storage and rain on their stability. Environmental Geology 55: 55-63. doi: 10.1007/s00254-007-0964-7

He K, Wang S, Du W and Wang S (2010) Dynamic features and effects of rainfall on landslides in the three gorges reservoir region, china: Using the xintan landslide and the large huangya landslide as the examples. Environmental Earth Sciences 59: 1267-1274. doi: 10.1007/s12665009-0114-5

Hooper A (2008) A multi-temporal insar method incorporating both persistent scatterer and small baseline approaches. Geophysical Research Letters 35: n/a-n/a. doi: 10.1029/2008gl034654

Hu X, Tang H, Li C and Sun R (2012) Stability of huangtupo riverside slumping mass ii\# under water level fluctuation of three gorges reservoir. Journal of Earth Science 23: 326-334. doi: 10.1007/s12583-012-0259-0

Hu XL, Tang HM, Li CD and Sun RX (2012) Stability of huangtupo i\# landslide under three gorges reservoir operation. Applied Mechanics and Materials 170-173: 8. doi: 10.4028/www.scientific.net/AMM.170-173.1116

Jackson S and Sleigh A (2000) Resettlement for china's three gorges dam: Socio-economic impact and institutional tensions. Communist and Post-Communist Studies 33: 223-241. doi: 10.1016/s0967-067x(00)00005-2

Jiang J, Ehret D, Xiang W, Rohn J, Huang L, Yan S and Bi R (2011) Numerical simulation of qiaotou landslide deformation caused by drawdown of the three gorges reservoir, china. Environmental Earth Sciences 62: 411-419. doi: 10.1007/s12665-010-0536-0

Jiang W-P, Huang B-Z and Ouyang H (2007) The monitoring technological method of landslide in huangtupo. Resources Environment \& Engineering 21: 575-578.

Jiao Y-Y, Song L, Tang H-M and Li Y-A (2014) Material weakening of slip zone soils induced by water level fluctuation in the ancient landslides of three gorges reservoir. Advances in Materials Science and Engineering 2014: 9. doi: 10.1155/2014/202340

Jin $Y$, Wen-xing J, Hu-feng $Y$ and Jiu-long $Z$ (2012) Dynamic variation rule of phreatic line in huangtupo landslide in the three gorges reservoir area. Rock and Soil Mechanics: 853-858.

Liu P, Li Z, Hoey T, Kincal C, Zhang J, Zeng Q and Muller J-P (2013) Using advanced insar time series techniques to monitor landslide movements in badong of the three gorges region, china. International Journal of Applied Earth Observation and Geoinformation 21: 253-264. doi: 10.1016/j.jag.2011.10.010

NOC (2014) Crosswavelet and wavelet coherence. Http://noc.Ac.Uk/usingscience/crosswavelet-wavelet-coherence.

Peng L, Xu S, Hou J and Peng J (2014) Quantitative risk analysis for landslides: The case of the three gorges area, china. Landslides: 1-18. doi: 10.1007/s10346-014-0518-5

Tang H, Hu X, Deng Q and Xiong C (2009) Research on the characteristics and slope deformation regularity of the badong formation in the three gorges reservoir area. Landslide disaster mitigation in three gorges reservoir, china. In: Wang F and Li T (eds), Springer Berlin Heidelberg, pp 87-113

Tang H, Li C, Hu X, Su A, Wang L, Wu Y, Criss R, Xiong C and Li Y (2014) Evolution characteristics of the huangtupo landslide based on in situ tunneling and monitoring. Landslides: 1-11. doi: 10.1007/s10346-014-0500-2 
This paper has to be cited as: Tomás, R., Li, Z., Lopez-Sanchez, J.M., Liu, P. \& Singleton, A. 2016. Using wavelet tools to analyse seasonal variations from InSAR time-series data: a case study of the Huangtupo landslide. Landslides, 13, 437-450, The final publication is available at Springer via: https://link.springer.com/article/10.1007\%2Fs10346-015-0589-y

Tomás R, Li Z, Liu P, Singleton A, Hoey T and Cheng X (2014) Spatiotemporal characteristics of the huangtupo landslide in the three gorges region (china) constrained by radar interferometry. Geophysical Journal International 197: 213-232. doi: 10.1093/gji/ggu017

Torrence C and Compo GP (1998) A practical guide to wavelet analysis. Bulletin of the American Meteorological Society 79: 61-78. doi: 10.1175/1520-0477(1998)079<0061:apgtwa>2.0.co;2

Tullos D (2009) Assessing the influence of environmental impact assessments on science and policy: An analysis of the three gorges project. Journal of Environmental Management 90, Supplement 3: S208-S223. doi: http://dx.doi.org/10.1016/i.jenvman.2008.07.031

Wang F-W, Zhang Y-M, Huo Z-T, Matsumoto T and Huang B-L (2004) The july 14, 2003 qianjiangping landslide, three gorges reservoir, china. Landslides 1: 157-162. doi: 10.1007/s10346-004-0020-6

Wang F, Zhang Y, Huo Z, Peng X, Araiba K and Wang G (2008) Movement of the shuping landslide in the first four years after the initial impoundment of the three gorges dam reservoir, china. Landslides 5: 321-329. doi: 10.1007/s10346-008-0128-1

Wang X, Chen Y, Song L, Chen X, Xie H and Liu L (2013) Analysis of lengths, water areas and volumes of the three gorges reservoir at different water levels using landsat images and srtm dem data. Quaternary International 304: 115-125. doi: http://dx.doi.org/10.1016/i.quaint.2013.03.041

Wen $\mathrm{B}$ and Chen $\mathrm{H}$ (2007) Mineral compositions and elements concentrations as indicators for the role of groundwater in the development of landslide slip zones: A case study of large-scale landslides in the three gorges area in china. Earth Science Frontiers 14: 98-106. doi: 10.1016/s1872-5791(08)60006-8

Xia M, Ren $G$ and Ma X (2013) Deformation and mechanism of landslide influenced by the effects of reservoir water and rainfall, three gorges, china. Natural Hazards: 1-16. doi: 10.1007/s11069013-0634-x

Xie L (2009) Complex geological characteristics and mechanism and control technical of landsliding of huangtupo at three gorges reservoir. Wuhan University of Technology 